\title{
Genetic Mapping and Nucleotide Diversity of Two Powdery Mildew Resistance Loci in Melon (Cucumis melo)
}

\author{
Cui Haonan,1,2 Ding Zhuo,,,2 Fan Chao, 1,2,3 Zhu Zicheng,,1,2 Zhang Hao, ${ }^{1,2}$ Gao Peng,, ${ }^{1,2} \dagger$ and Luan Feishi1,2,† \\ ${ }^{1}$ Key Laboratory of Biology and Genetic Improvement of Horticulture Crops (Northeast Region), Ministry of Agriculture and Rural Affairs, \\ Harbin, Heilongjiang Province, 150030, China \\ ${ }^{2}$ College of Horticulture and Landscape Architecture, Northeast Agricultural University, Harbin, Heilongjiang Province, 150030, China \\ ${ }^{3}$ Institute of Crop Cultivation and Tillage, Heilongjiang Academy of Agricultural Sciences, Harbin, Heilongjiang Province, 150030, China \\ Accepted for publication 3 July 2020.
}

\begin{abstract}
Powdery mildew (PM) significantly and negatively affects the yield and quality of melon (Cucumis melo) worldwide. Race $2 \mathrm{~F}$ is the predominant physiological race of the pathogen Podosphaera xanthii in many regions. We used accessions PMR $6\left(\mathrm{P}_{1}\right.$; resistant to $\left.\mathrm{PM}\right)$ and M1-7 $\left(\mathrm{P}_{2}\right.$; susceptible to $\left.\mathrm{PM}\right)$ to analyze the inheritance of resistance to $\mathrm{PM}$ (race $2 \mathrm{~F}$ ). The ratio between resistant and susceptible individuals fits a Mendelian segregation ratio of 13:3 in a total of $256 \mathrm{~F}_{2}$ individuals and 1:1 in $\mathrm{BC}_{1} \mathrm{P}_{2}$. The resistance to PM in PMR 6 was governed by two genes: a dominant (AA) gene with an epistatic effect and a recessive gene (bb). Only individuals with $a a B B$ or $a a B b$ genotypes were susceptible to PM. Two PM resistance loci, Pm2.1 and pm12.1, were mapped on chromosomes 2 and 12 by bulked segregant analysis and secondary mapping by
\end{abstract}

ABSTRACT

Melon (Cucumis melo L., Cucurbitaceae; 2n=2x=24) (YusteLisbona et al. 2011b) is a valuable cash crop that is cultivated across temperate and tropical regions of the world. China produces about eight million tons of melon annually, accounting for $51 \%$ of global production. Powdery mildew (PM), caused by two fungi, Podosphaera xanthii [syn. Sphaerotheca fuliginea] and Golovinomyces cichoracearum, is a common foliar disease in melon all year round under field and greenhouse conditions (Wang et al. 2016), and one of the main factors negatively affecting productivity and fruit quality.

$P$. xanthii was first reported in California in 1925. Since then more than 28 physiological races including races $0,1,2 \mathrm{US}, 2$ France, 3, 4, 5, N1 (race 6), N2 (race 7), N3, and N4 have been characterized based on the reactions of $P$. xanthii isolates to melon differential lines (Hosoya et al. 2000). McCreight (2006) reported eight variants of race 1 and six variants of race 2 by differentiating the reactions of 22 melon accessions to 28 putative races of $P$. xanthii. Kim et al.

${ }^{\dagger}$ Corresponding authors: L. Feishi; luanfeishi@neau.edu.cn, and G. Peng; gaopeng_neau@163.com

Funding: This study was funded by the National Nature Science Foundation of China (No. 31672177), the "Academic Backbone" Project of Northeast Agricultural University (No. 16XG06), the "Young Talents" Project of Northeast Agricultural University (No. 14QC09), the College Youth Innovation Talent Training Project of Heilongjiang Province (No. UNPYSCT-2016136), and the China Agriculture Research System (CARS-25).

Author contributions: C.H., F.C., G.P., and L.F. conceived and designed the experiments. D.Z., Z.Z., Z.H. performed the field experiments. C.H. performed the data analysis and wrote the manuscript. All authors read and approved the final manuscript.

*The $\boldsymbol{e}$-Xtra logo stands for "electronic extra" and indicates that two supplementary figures and one supplementary table are published online.

The author(s) declare no conflict of interest.

C 2020 The American Phytopathological Society quantitative trait loci analysis with 18 markers. A new marker-assisted selection system to identify melon genotypes resistant or susceptible to PM was developed and tested in 93 melon accessions. Nucleotide diversity $(\pi)$ and fixation index (Fst) for the two PM resistance loci were estimated using resequencing data of 336 melons from three groups: C. melo subsp. agrestis, Cucumis melo subsp. melo, and the intermediate type. The lowest $\pi$ was observed in $C$. melo ssp. agrestis, and the highest Fst value was between $C$. melo ssp. agrestis and $C$. melo ssp. melo. The findings provide a promising tool that can be used to accelerate breeding for durable resistance to PM.

Keywords: genetics and resistance, selection pressure analysis
(2016) recently reported a new race, race N5, based on its unique response to 10 standard differential lines when compared with seven known races of $P$. xanthii (races $1, \mathrm{~N} 1, \mathrm{~N} 2,5, \mathrm{~A}, \mathrm{~S}, \mathrm{O}$ ). The prevalence of physiological races in any one area appears to be mainly determined by growing season, geographic region, and melon variety. Races 1, 2, and 3 occurred mostly in America and Brazil, whereas 0, 4, and 5 were the predominant races in France (Bardin et al. 1999a; Hudson et al. 2018; Křístková et al. 2009). In China, races 1 and $2 \mathrm{~F}$ were the most widespread (Hao et al. 2015; Wang et al. 2011).

For many years, fungicides have been widely applied to control $\mathrm{PM}$ in melon with limited success, resulting in fungicide resistance of PM pathogens (Hollomon et al. 2002; Lebeda et al. 2010). Hence, the development of melon varieties resistant to PM is the most practical and economic approach for environmentally safe and sustainable long-term control of PM (Ning et al. 2014; YusteLisbona et al. 2011a, b). Since Jagger and Scott first reported melons resistant to PM in 1937 (Pryor et al. 1946), breeders have developed and deployed more than 30 PM-resistant germplasm worldwide (Daryono and Yambise 2018; Hudson et al. 2018; McCreight 2002, 2006). However, recent reports revealed that the rapid variability and spread of PM pathogen populations has been leading to the breakdown of PM resistance in melon. Therefore, it is a high priority to develop PM-resistant varieties by pyramiding race-specific genes (Hosoya et al. 2000; McCreight et al. 2005). However, numerous problems have been associated with in vivo screening and traditional breeding for resistance to PM, including the fact that this approach is time-consuming, labor-intensive, and dependent on the environment for disease development (Ning et al. 2014). Molecular markers that are tightly linked to specific resistance genes provide a powerful tool for marker-assisted selection of resistance at the seed/seedling stage, thus eliminating the growing time and nursery costs for testing adult plants and making the breeding process more efficient (Yuste-Lisbona et al. 2011a). 
Previous marker-trait association studies including bulked segregant analysis (BSA) and genome-wide association studies (GWAS) have revealed several genes and quantitative trait loci (QTLs) conferring resistance to PM in chromosomes or linkage groups 2, 5, and 12, including Pm-1, Pm-2, Pm-3, Pm-4, Pm-5, Pm6 (Cohen et al. 1990; Dogimont 2011), Pm-R, Pm-W, Pm-X, Pm-Y (Perin et al. 2002; Pitrat 1991; Yuste-Lisbona et al. 2011a, b), Pm-x1,Pm-x3,Pm-x5 (Fazza et al. 2013), Pm-Edisto47-1, $P m$-Edisto47-2 (Ning et al. 2014), Pm-2F (Zhang et al. 2012), PmpxA, Pm-pxB (Fukino et al. 2008), Pm-An (Wang et al. 2011), PmV.1, PmXII.1 (Perchepied et al. 2005), BPm12.1 (Li et al. 2017), and $p m-S$ (McCreight and Coffey 2011). Amanullah (2016) detected 12 GWAS signals for PM resistance, seven of which have been reported in previous research and another five loci were novel.

However, no genes underlying resistance QTLs have been identified and there is a need to identify and characterize gene loci conferring PM resistance in melon. The objective of the present study was to identify PM resistance loci associated with resistance to $P$. xanthii race $2 \mathrm{~F}$ in a biparental population using BSA coupled with genomic technologies. Additionally, we aimed to further characterize the PM resistance loci interval associated with PM resistance in 336 melon accessions and evaluate selected single nucleotide polymorphisms (SNPs) in marker-assisted selection for PM resistance.

\section{MATERIALS AND METHODS}

Plant material. The segregating population used in the present study consisted of $256 \mathrm{~F}_{2}$ individuals derived from a cross between PMR 6 (the female parent moderately resistant to PM) and M1-7 (the male parent susceptible to many PM races). Thirteen differential lines (Iran H, TopMark, Védrantais, PMR 45, PMR 5, WMR 29, Edisto 47, PI 414723, MR-1, PI 124111, PI 124112, PMR 6, and Nantais Oblong) were used as differential control to characterize the $P$. xanthii race (Bardin et al. 1999a; Hosoya et al. 1999, 2000; McCreight 2006).

In the summer of 2017, $\mathrm{P}_{1}$ (M1-7), $\mathrm{P}_{2}$ (PMR 6), $\mathrm{F}_{1}$ (M1-7×PMR 6), $\mathrm{F}_{2}\left(\mathrm{~F}_{1} \times \mathrm{F}_{1}\right), \mathrm{BC}_{1} \mathrm{P}_{1}\left(\mathrm{~F}_{1} \times \mathrm{M} 1-7\right)$, and $\mathrm{BC}_{1} \mathrm{P}_{2}\left(\mathrm{~F}_{1} \times \mathrm{PMR} 6\right)$ and the 13 differential hosts were grown in a greenhouse at Xiangyang Experiment Agricultural Station of Northeast Agricultural University, Harbin $\left(44^{\circ} 04^{\prime} \mathrm{N}, 125^{\circ} 42^{\prime} \mathrm{E}\right)$, China. Each of the $\mathrm{P}_{1}$, $\mathrm{P}_{2}$, and $\mathrm{F}_{1}$ generations were grown with 15 plants, each of the $\mathrm{BC}_{1} \mathrm{P}_{1}$ and $\mathrm{BC}_{1} \mathrm{P}_{2}$ generations were represented by 100 plants, each of the 13 differential hosts was planted with five plants, and $\mathrm{F}_{2}$ was planted for a total of 256 plants. The experiments were managed following standard horticultural procedures for typical climatic conditions in Harbin. Melon genotypes (336) were used for analysis of nucleotide diversity in target segments. Melon materials were divided into three groups: $C$. melo subsp. agrestis, C. melo subsp. melo, and intermediate type (interspecific between the two species).

Phenotyping for PM resistance. PM isolates were collected from heavily PM-infected melon plants in 2016. The pathogen was isolated by a single spore method, and then inoculated on the leaves of the 13 differential melon lines. The isolated pathogen was determined as race $2 \mathrm{~F}$ according to differential reactions of these 13 lines, described by McCreight (2006).

The plants of $\mathrm{P}_{1}, \mathrm{P}_{2}, \mathrm{~F}_{1}, \mathrm{~F}_{2}, \mathrm{BC}_{1} \mathrm{P}_{1}$, and $\mathrm{BC}_{1} \mathrm{P}_{2}$ were inoculated with $P$. xanthii race $2 \mathrm{~F}$ using a spore suspension of $1 \times 10^{6}$ conidia/ $\mathrm{ml}$ (as counted with a hemacytometer), Preparation of the spore suspension and inoculation were completed within $2 \mathrm{~h}$ after spore collection. The spore suspension contained $0.01 \%$ Tween 20 and was applied until runoff during the flowering stage under controlled conditions $\left(65 \%\right.$ relative humidity, $28^{\circ} \mathrm{C} / 16 \mathrm{~h}$ light and $20^{\circ} \mathrm{C} / 8 \mathrm{~h}$ dark) (Xu et al. 2019; Zhang et al. 2011). The responses of the plants to race $2 \mathrm{~F}$ were scored 10 days after inoculation using a scale of 0 to 5 assigned to each plant as previously described by Bardin et al. (1999b), where 0 = asymptomatic; 1 = minor symptoms with less than $10 \%$ leaf covered by spores; $2=$ moderate symptoms with 10 to $30 \%$ leaf covered by spores; $3=$ severe symptoms with 30 to $60 \%$ leaf covered by spores; $4=$ severe symptoms with 60 to $90 \%$ leaf covered by spores; and $5=$ severe symptoms with more than $90 \%$ leaf covered by spores. Typical symptoms for each of the classes are shown in Figure 1. A percent disease index (PDI) proposed by Wheeler and Kent (1969) was calculated as follows:

$\mathrm{PDI}=\frac{\text { Sum of numerical disease ratings }}{\text { number of plants evaluated } \times \text { maximum of disease rating scale }} \times 100$

The responses of melon plants to PM were classified using PDI as follows: resistant $(\mathrm{R})<40$, moderately resistant $(\mathrm{MR})=40$ to 60 , and susceptible $(\mathrm{S})>60$. A $\chi^{2}$ test $\left(\chi^{2}\right)$ was performed to determine the goodness of fit of observed and expected segregation ratios of the $\mathrm{F}_{2}$ for markers and PM responses.

DNA extraction. Genomic DNA was individually isolated from each of the $256 \mathrm{~F}_{2}$ plants and two parents using the modified cetyltrimethylammonium bromide method (Allen et al. 2006). The DNA concentration of each sample was estimated using a SMA3000 spectrophotometer (Plextech, Shenzhen, China) and electrophoresis on $1 \%$ agarose gels.

BSA. According to the evaluation of responses to PM based on percent disease index $(R<40$ and $S>60)$, two bulks, namely the $R$ and $\mathrm{S}$ pools, were generated from $\mathrm{F}_{2}$ plants for the BSA in 2017; each consisted of 20 extremely resistant and 20 susceptible individual plants. The DNA samples of two bulks and two parents were sequenced on an Illumina HiSeqTM Xten platform (Biomarker, Beijing, China) to produce 150 base paired-end reads.

The genome-wide resequencing data from two parents were aligned with the reference genome of DHL92 (Jordi et al. 2012) using a Burrows-Wheeler Aligner for detecting nonsynonymous SNPs (nsSNPs). The SNPs were recognized by samtools $1.0(\mathrm{Li}$ et al. 2009) from a BAM format file and annotated using the SnpEff tool (Cingolani et al. 2012).

The SNP index was estimated as follows: M presents PMR 6, T presents M1-7, while aa and bb are equal to the genotypes of the Rand S-bulks, respectively. Maa and Taa represent the depth of the aa population derived from $\mathrm{M}$ and $\mathrm{T}$, respectively. $\mathrm{Mbb}$ and $\mathrm{Tbb}$ represent the depth of the bb population derived from $\mathrm{M}$ and $\mathrm{T}$, respectively. Therefore,

$$
\begin{gathered}
\text { SNP_index }(\mathrm{aa})=\mathrm{Maa} /(\mathrm{Taa}+\mathrm{Maa}) \\
\text { SNP_index }(\mathrm{bb})=\mathrm{Mbb} /(\mathrm{Tbb}+\mathrm{Mbb}) \\
\Delta(\mathrm{SNP} \text { _index })=\mathrm{SNP} \_ \text {index }(\mathrm{aa})-\mathrm{SNP} \_ \text {index }(\mathrm{bb})
\end{gathered}
$$

The $\Delta$ (SNP_index) threshold of a nonreference genome was determined as follows (Zheng et al. 2018): $\Delta$ (SNP_index) $>0.99$ marker was selected as the threshold of significant association with traits, while the marker $>$ the threshold was the marker of significant association with traits.

Kompetitive allele specific PCR (KASP) genotyping. For each SNP, two allele-specific forward primers and one common reverse primer were designed by LGC Genomics. Using these primers, KASP assays were performed in 1,536-well plates (KBS0751-001; KBioscience, UK) in 1- $\mu$ l final reaction volumes containing $1 \times$ KASP reaction mix (KBS-1016-011; KBioscience), $12 \mathrm{nmol} / \mathrm{liter}$ of each allele-specific forward primer, $30 \mathrm{nmol} / \mathrm{liter}$ reverse primer, and $4 \mathrm{ng}$ of genomic DNA. The amplifications were performed on a GenePro Thermal Cycler (Hydrocycler) with the following cycling conditions: $15 \mathrm{~min}$ at $94^{\circ} \mathrm{C} ; 10$ touch-down cycles 
of $20 \mathrm{~s}$ at $94^{\circ} \mathrm{C}$ and $60 \mathrm{~s}$ at 65 to $57^{\circ} \mathrm{C}$ (with the annealing temperature for each cycle reduced by $0.8^{\circ} \mathrm{C}$ per cycle); and 26 to 42 cycles of $20 \mathrm{~s}$ at $94^{\circ} \mathrm{C}$ and $60 \mathrm{~s}$ at $57^{\circ} \mathrm{C}$. Fluorescence detection of the reaction products was performed using an Omega Fluorostar scanner (BMG PHERAstar), and the data were analyzed using KlusterCaller 1.1 software (Kbioscience). Following completion of the KASP, reaction plates were read and the data analyzed using SNPviewer (Kbioscience).

Cleaved amplified polymorphic sequence (CAPS) markers development and secondary mapping by QTL analysis based on BSA results. QTL analysis was performed to narrow down the target interval of the resistance gene and reduce discrepancies caused by experimental errors in artificial inoculations. Additionally, SNP-based cleaved amplified polymorphic sequence (CAPS) markers were designed and distributed in the genomic region by the $\Delta$ (SNP_index) analysis in Primer Premier 6.0. The primers of CAPS markers were synthesized by Sangon Biotech to screen for polymorphism between two parental lines and between two DNA bulks for genotyping of the $F_{2}$ population. Genetic linkage map construction was performed using the IciMapping V3.3 software (Institute of Crop Science, Chinese Academy of Agricultural Sciences, Beijing, China) (Meng et al. 2015), and all the markers were grouped at a minimum logarithm of odd (LOD) score of 6.0. The software package QTL analysis was also performed with IciMapping V3.3 (Meng et al. 2015). Composite interval mapping (CIM) was used to search QTL for PM resistance on one chromosome, and QTLs with a LOD score $\geq 5.0$ were considered as the available loci for detection. R/qtl (Broman et al. 2003) were used to analyze PM resistance loci, the function effect plot uses the multiple imputation method to obtain estimates of the genotype-specific phenotype averages, taking account of missing genotype data. The estimates are weighted averages of the estimates from the multiple imputations, with the individual imputations being weighted by $10^{\mathrm{LOD}}$. The standard errors (SEs) include the imputation error.

Validation of PM resistant markers for MAS breeding. PM resistance markers linked to resistance loci were validated using 93 melon accessions to investigate the correlation between the genotypic and phenotypic data.

Neutrality test of the two candidate locations. The nucleotide diversity $(\pi)$ and fixation index (Fst) were estimated by Vcftools and plotted with R software. Fst is usually used to measure the genetic distance between populations, and $\pi$ is mainly applied to measure the nucleotide divergency of each site (Danecek et al. 2011).

\section{RESULTS}

Determination of the physiological race of $P$. xanthii. Thirteen differential lines were inoculated with the PM strain isolated from the infected plants. Eight differential lines, specifically lines PMR 5, PMR 6, Edisto 47, WMR 29, PI 414723, MR-1, PI 124111, and PI 124112, were resistant to this PM strain, whereas five lines, Iran H, Védrantais, Top Mark, Nantais Oblong, and PMR

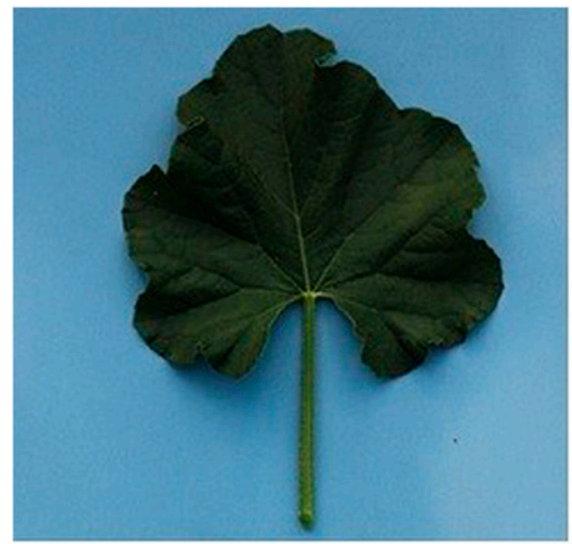

Class 0

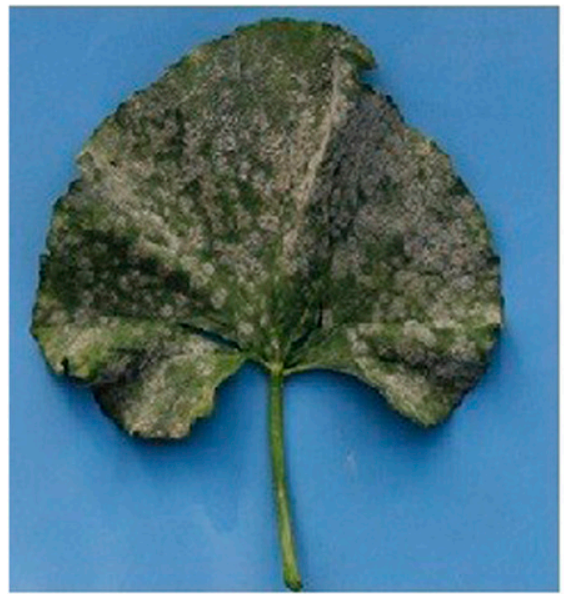

Class 3

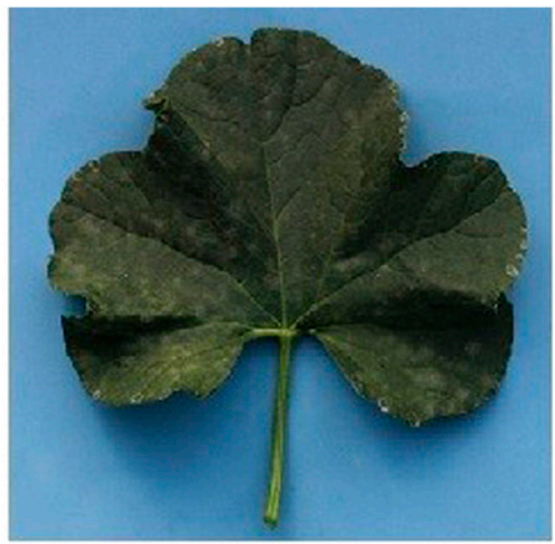

Class 1

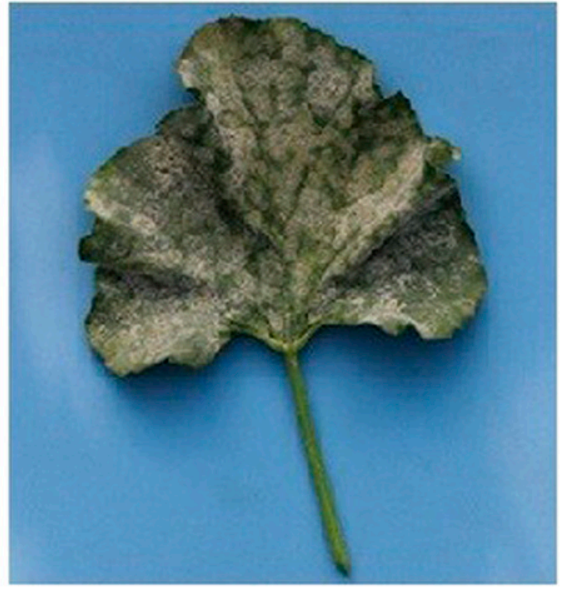

Class 4

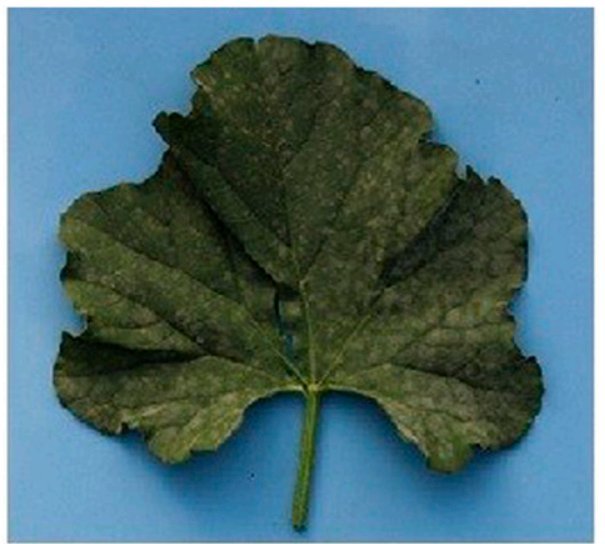

Class 2

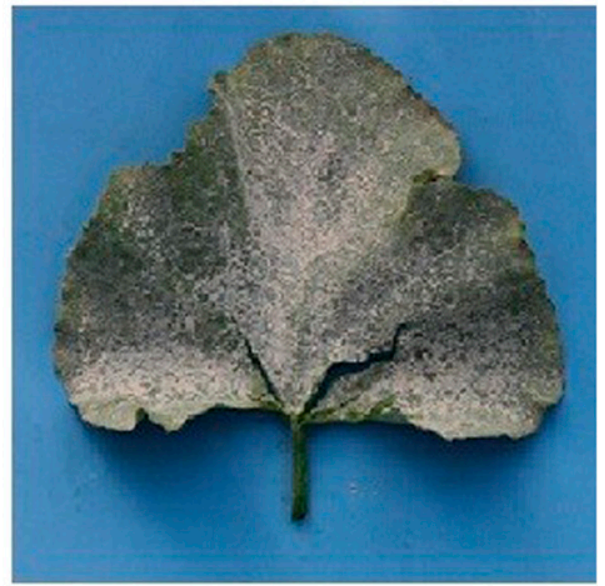

Class 5

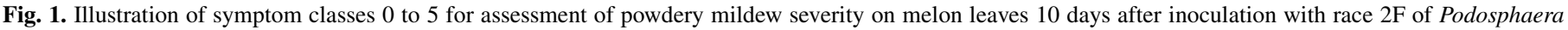
xanthii. 
45 were susceptible (Table 1) demonstrating that the isolate for inoculation was race $2 \mathrm{~F}$ of $P$. xanthii (McCreight 2006). PMR 45 was susceptible to the isolate, confirming that the isolate is race 2 instead of race 1, whereas resistance responses of Edisto 47 and PI 414723 determined that this isolate was race $2 \mathrm{~F}$ instead of $2 \mathrm{US}$. Therefore, the physiological race of PM used in this study is $P$. xanthii race $2 \mathrm{~F}$.

Genetic analysis for resistance to PM. The PDI of the parental line PMR 6 was less than 40, demonstrating resistance to PM after inoculation with race $2 \mathrm{~F}$ of $P$. xanthii; conversely, M1-7 was severely infected with a PDI greater than 60. Supplementary Figure S1 shows abundant sporulation of $P$. xanthii on M1-7 under the scanning electron microscope. Both the $\mathrm{F}_{1}$ and $\mathrm{BC}_{1} \mathrm{P}_{1}$

TABLE 1. Reactions of 13 differential melon lines to race $2 \mathrm{~F}$ of powdery mildew (Podosphaera xanthii)

\begin{tabular}{lcc}
\hline Accession & Percent disease index $(\text { PDI })^{\mathrm{a}}$ & Reaction level $^{\mathrm{b}}$ \\
\hline IranH & 93.3 & $\mathrm{~S}$ \\
Topmark & 90.2 & $\mathrm{~S}$ \\
Vedrantais & 87.9 & $\mathrm{~S}$ \\
PMR 45 & 92.5 & $\mathrm{~S}$ \\
PMR 5 & 12.3 & $\mathrm{R}$ \\
WMR 29 & 24.6 & $\mathrm{R}$ \\
Edisto 47 & 27.7 & $\mathrm{R}$ \\
PI 414723 & 21.5 & $\mathrm{R}$ \\
MR-1 & 25.6 & $\mathrm{R}$ \\
PI 124111 & 22.7 & $\mathrm{R}$ \\
PI 124112 & 24.8 & $\mathrm{R}$ \\
PMR 6 & 31.8 & $\mathrm{R}$ \\
Nantais & 93.4 & $\mathrm{~S}$
\end{tabular}

a $\mathrm{PDI}=[$ sum of numerical disease ratings/(number of plants evaluated $\times$ maximum of disease rating scale) $] \times 100$, where disease was assessed using a 0 to 5 rating scale. Values are means of five plants per accession.

b $\mathrm{S}=$ susceptible, $\mathrm{R}=$ resistant. generations were resistant to $\mathrm{PM}$, while the $\mathrm{BC}_{1} \mathrm{P}_{2}$ generation exhibited a $1: 1$ ratio of $\mathrm{R}(n=52)$ to $\mathrm{S}\left(n=58 ; \chi^{2}=0.327, P=0.567\right)$. Among the $256 \mathrm{~F}_{2}$ progenies evaluated in 2017 (Fig. 2), the ratio of $\mathrm{R}(n=200)$ to $\mathrm{S}(n=56)$ fit a Mendelian $\mathrm{F}_{2}$ segregation ratio of $13: 3$ (R:S; $\chi^{2}=1.641, P=0.200$ ) (Table 2 ), suggesting two genes were associated with resistance to race $2 \mathrm{~F}$ in PMR 6 . Of these, one is dominant and the other is recessive.

Two resistance genes detected on chromosomes 2 and 12 by BSA. Two DNA pools were sequenced by the Beijing Genomics Institute to generate BSA preliminary positioning data (data not shown). The background was relatively consistent throughout the pools, and two significant peaks were detected on chromosomes 2 and 12 (Fig. 3A), suggesting that genes that provide resistance to PM might be positioned on chromosome 2 or 12 . The thresholds for chromosomes 2 and 12 were 0.62 and 0.47 , respectively. The intervals on chromosomes 2 and 12 showed the SNP index $(\Delta)$ higher than the thresholds, suggesting associations with resistance of the candidate intervals of 0 to $2,274,414 \mathrm{bp}$ on chromosome 2 (Fig. 3B) and 22,357,701 to 24,247,032 bp on chromosome 12 (Fig. $3 \mathrm{C})$. The BSA result supported the results of genetic analysis of six generations, meaning two putative loci resistant to PM exist in PMR 6.

Secondary mapping by QTL analysis based on BSA results. The primers for KASP and CAPS markers were designed using resequencing data of two parents based on the SNPs detected in the candidate segments. A total of 18 pairs of polymorphic primers for chromosomes 2 (nine pairs) and 12 (nine pairs) were used for genotyping of $256 \mathrm{~F}_{2}$ individuals. A linkage map for 18 markers was constructed and the QTLs were analyzed by QTL IciMapping. One resistance locus was mapped to the locus Pm2.1 on chromosome 2 in the interval between two KASP markers, specifically snp5 and snp6 (Fig. 4A, Table 3) and the other resistance locus was mapped to the locus pm12.1 on chromosome

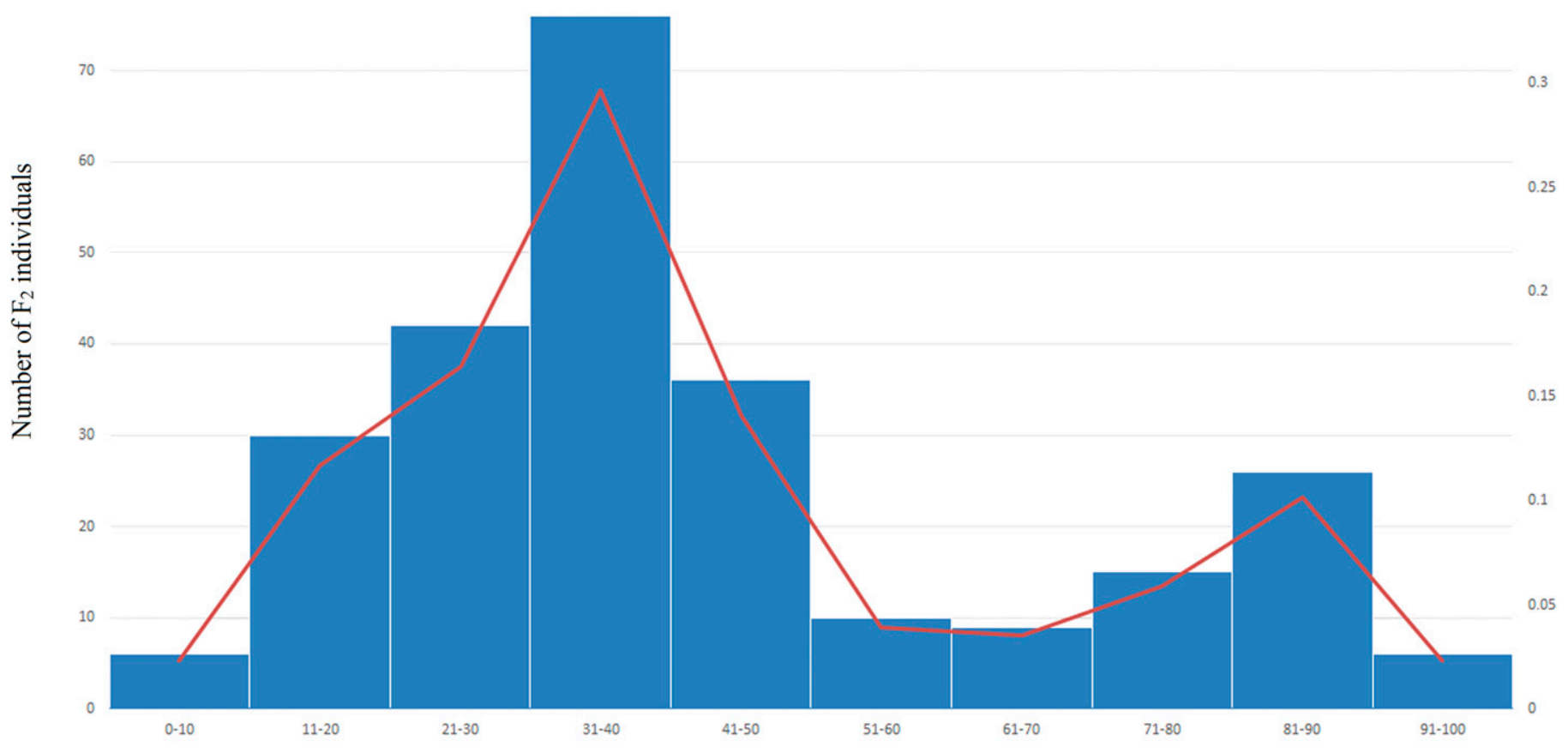

Percent disease index

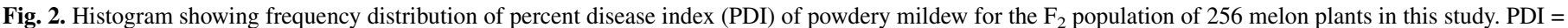

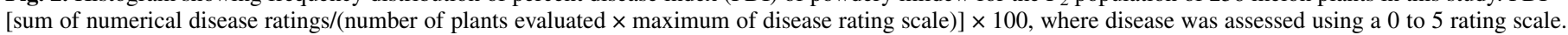


12 in the region between two CAPS markers, specifically $12 \mathrm{C} 8$ and $12 \mathrm{C} 13$ (Fig. 4B, Table 3).

Sequence of this region in the melon genome CM3.5.1 was analyzed according to the melon genome automated annotation database (https://melonomics.net). On chromosome 2, there are two candidate genes. MELO3C015353 is a disease resistance protein, and MELO3C015354 is a disease resistance family protein/leucinerich repeat (LRR) family protein. On chromosome 12, five genes identified in candidate genomic region were predicted to be candidate resistance genes, and functional annotation of these candidate genes revealed their role in the ankyrin repeat family, glycine-rich cell wall structural, and a DUF4283 domain protein (Table 4).

TABLE 2. Disease response means of $\mathrm{P}_{1}, \mathrm{P}_{2}, \mathrm{~F}_{1}, \mathrm{~F}_{2}, \mathrm{BC}_{1} \mathrm{P}_{1}$, and $\mathrm{BC}_{1} \mathrm{P}_{2}$ after artificial inoculation with Podosphaera xanthii race $2 \mathrm{~F}$ in greenhouse evaluation of melon germplasm, $\chi^{2}$ verification of $\mathrm{F}_{2}$ and $\mathrm{BC}_{1} \mathrm{P}_{2}$, and segregation ratio between resistant $(\mathrm{R})$ and susceptible $(\mathrm{S})$ individuals

\begin{tabular}{lcrrcccc}
\hline Year & Generation & $\mathrm{R}$ & $\mathrm{S}$ & Expected ratio & Actual ratio & $\chi^{2}$ \\
\hline 2017 & $\mathrm{P}_{1}$ & 0 & 15 & - & - & - \\
& $\mathrm{P}_{2}$ & 15 & 0 & - & - & - \\
& $\mathrm{F}_{1}$ & 15 & 0 & - & - & - \\
& $\mathrm{BC}_{1} \mathrm{P}_{1}$ & 105 & 0 & - & - & - \\
& $\mathrm{BC}_{1} \mathrm{P}_{2}$ & 52 & 58 & $3: 1$ & $0.9: 1$ & - \\
& $\mathrm{F}_{2}$ & 200 & 56 & $13: 3$ & $12.5: 3.5$ & 0.327 \\
\hline
\end{tabular}

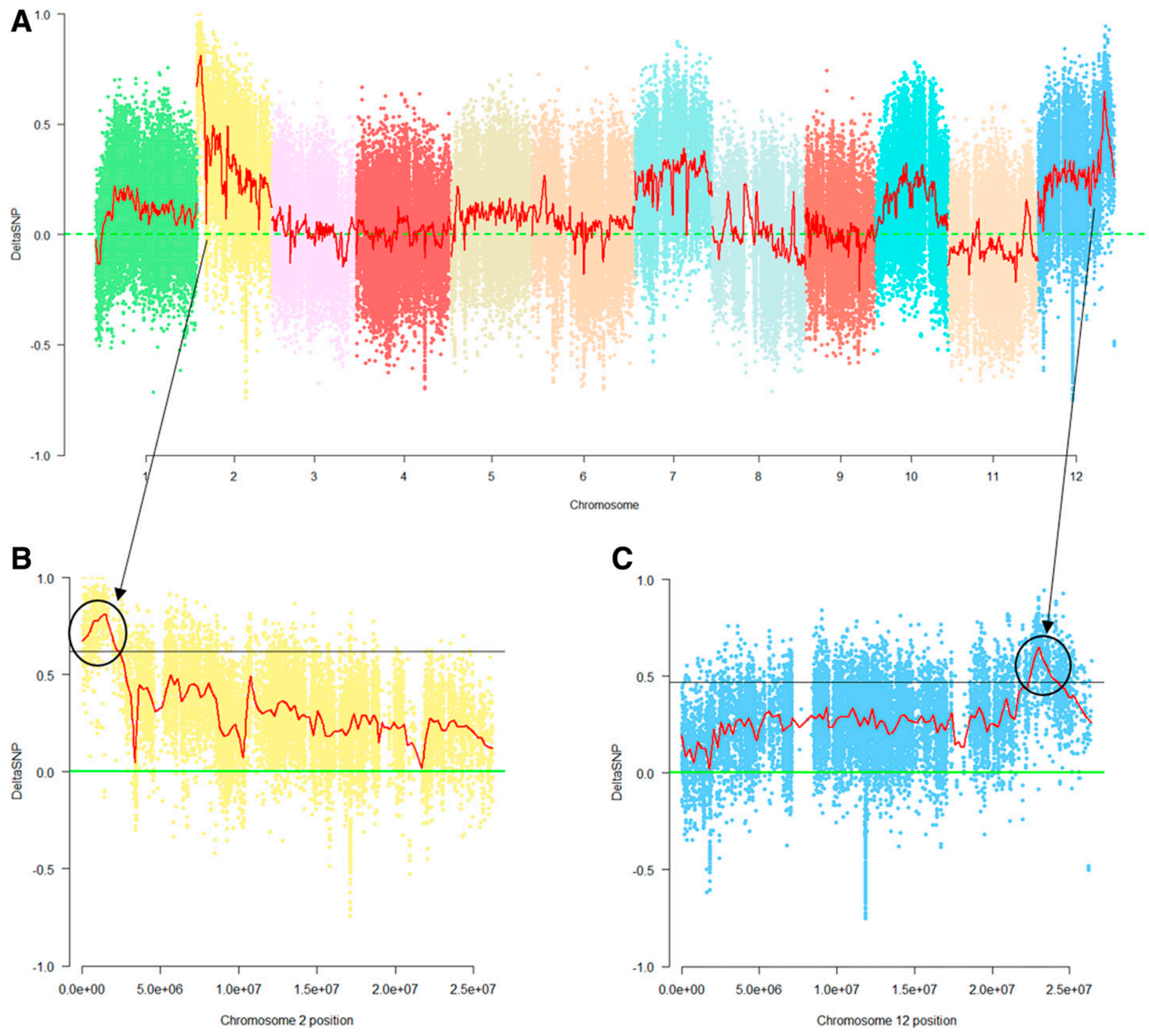

Fig. 3. A, Single nucleotide polymorphism (SNP) index calculated with the resistant and susceptible pools against powdery mildew across the melon genome where the horizontal axis presents the position of 12 chromosomes and the vertical axis represents the SNP index. B, SNP index on chromosome 2. C, SNP index on chromosome 12. The black line indicates the threshold value estimated by Loess regression. 
Interaction analysis of two resistance loci. The interaction between two loci was analyzed with R/qtl based on the genotype and phenotype of each individual plant in an $F_{2}$ segregating population. The plant carrying dominant locus $P m 2.1$ was resistant to PM regardless of the genotype of the locus pm12.1, whereas when the locus Pm2.1 was homozygous for the recessive locus, plants with the recessive homozygous locus pm12.1 were resistant to PM but plants with dominant locus pm12.1 were susceptible to PM (Fig. $4 C)$. Therefore, only the genotypes of $a a B B$ and $a a B b$ were susceptible to PM. The results demonstrated that two dominant epistatic loci were associated with resistance to race 2F in PMR 6, among which, one is dominant and the other is recessive, supporting the results of genetic analysis of $\mathrm{P}_{1}, \mathrm{P}_{2}, \mathrm{~F}_{1}, \mathrm{~F}_{2}, \mathrm{BC}_{1} \mathrm{P}_{1}$, and $\mathrm{BC}_{1} \mathrm{P}_{2}$.

Evaluation of markers linked to $P M$ resistance for MAS. The two markers linked to $P m 2.1$ and $p m 12.1$ were screened across 93 melon accessions to verify their potential application for MAS in melon breeding. For the marker linked to Pm2.1, only 5 of 93 accessions mismatched between Pm2.1 genotype and phenotype, with mean coincidence of $94.6 \%$. Among them, five accessions were the genotypes of the resistant parent PMR 6 but susceptible to $P$. xanthii race $2 \mathrm{~F}$. The mean coincidence of the 93 accessions between the pm12.1 genotype and phenotype were $92.4 \%$, among which seven were the genotype of PMR 6 but susceptible to P. xanthii race 2 F (Supplementary Fig. S2).

Analysis of nucleotide diversity in target segments based on melon accessions. Melon materials were divided into three groups: C. melo ssp. agrestis, C. melo ssp. melo, and intermediate type (interspecific between the two species). Three-hundred and thirty-six melons were inoculated with race $2 \mathrm{~F}$ of $P$. xanthii, showing that all $C$. melo ssp. agrestis were susceptible to PM and all disease-resistant materials are $C$. melo ssp. melo based on the previous work of our laboratory and other researchers (Amanullah,
A Chromosome2

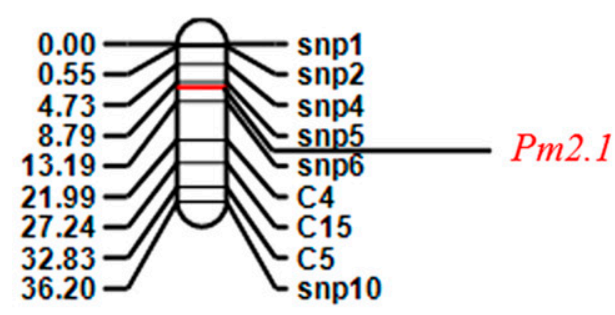

\section{B Chromosome12}

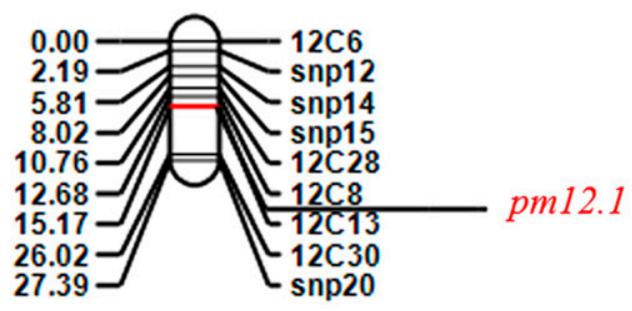

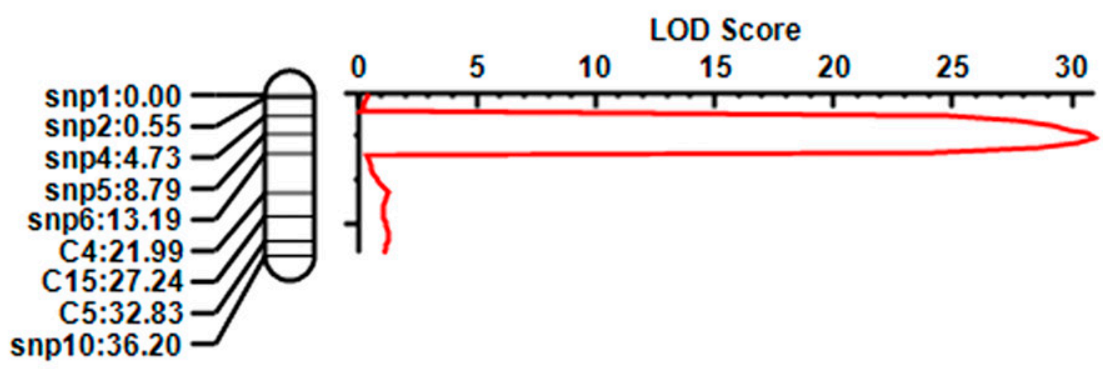

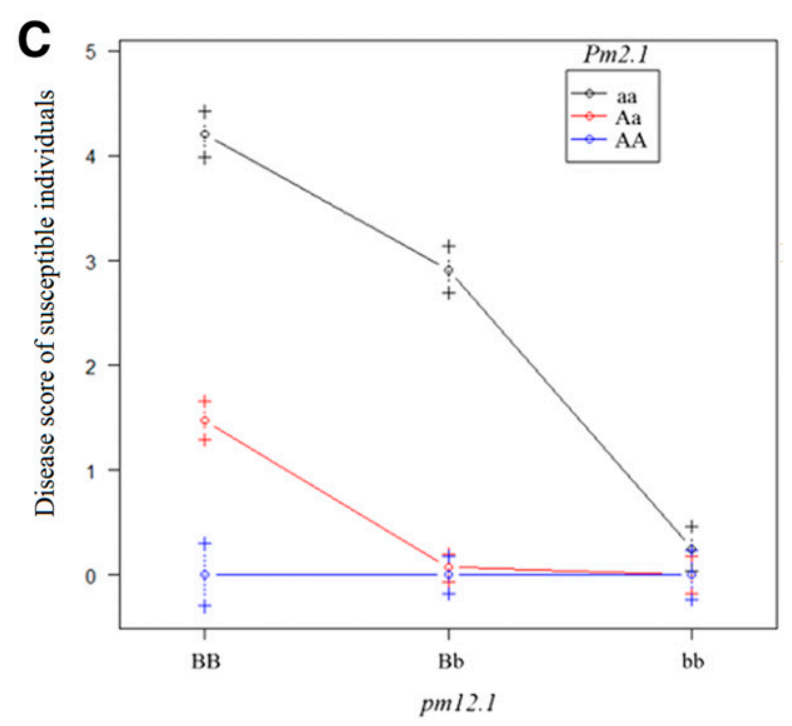

Fig. 4. A, Linkage map of the candidate region and logarithm of odds (LOD) scores of powdery mildew resistance locus Pm2.1 on melon chromosome 2 . B, Linkage map of the candidate region and LOD scores of pm12.1 on chromosome 12. C, Prediction of the interaction of these two resistance loci based on genotyping and phenotyping of the $\mathrm{F}_{2}$ population of 256 melon plants in this study. The standard errors (SEs) include the imputation error. Error bars are \pm 1 SE. 
2016; Ma et al. 2009). There are reports that detected two independent sets of domestication sweeps, resulting in diverse characteristics of the two subspecies C. melo. ssp. melo and C. melo ssp. agrestis during melon breeding (Zhao et al. 2019). Therefore, the target candidate regions were resequenced for pressure analysis in 336 accessions of the three melon groups (154 C. melo ssp. agrestis, 76 intermediate type, and 106 C. melo ssp. melo). The Fst values among the three groups were determined to evaluate the degree of differentiation. The Fst value of the candidate segment on chromosome 2 was consistent with that on chromosome 12. The highest degree of differentiation was detected between $C$. melo ssp. agrestis and C. melo ssp. melo, followed by between C. melo ssp. agrestis and the intermediate type, and between $C$. melo ssp. melo and the intermediate type (Fig. 5A and C).

Nucleotide diversity $(\pi)$ in the three groups was estimated to determine the degree of polymorphism per site between two DNA sequences in all possible pairs in the two candidate segments. Except for intervals of 985,000 to 990,000 bp on chromosome 2 and $22,880,000$ to $22,900,000$ bp on chromosome 12 , the lowest $\pi$ value was detected in C. melo ssp. agrestis, followed by C. melo ssp. melo and the intermediate type (Fig. 5B and D).

\section{DISCUSSION}

Globally, PM outbreaks have resulted in a significant decrease in yield and fruit quality of melon because mycelia often cover the leaves causing leaf necrosis and premature death of the plants; this leads to major economic losses in melon production. To develop a durable PM-resistant melon, it is critical to understand the pathogenic species and races that dominate in the target region of melon production.

P. xanthii and G. cichoracearum (syn. Erysiphe cichoracearum) are the most important pathogenic PM species in the family Cucurbitaceae. G. cichoracearum was recognized to be the dominant pathogen in most regions of the world before 1958; however, $P$. xanthii is currently emerging as the predominant pathogen in most countries (Bardin et al. 1999a; Hudson et al. 2018; Hosoya et al. 1999; McCreight 2006; Ning et al. 2014; Pino et al. 2002; Zhang et al. 2012). P. xanthii occurs more frequently in subtropical and tropical regions as well as in greenhouse crops, whereas G. cichoracearum is common in field environments of the temperate and colder regions (Ning et al. 2014; Sathishkumar et al. 2016). The latter is the predominant pathogen in China (Cheng et al. 2011; Ma et al. 2011; Zhang et al. 2012).

Thirteen melon hosts are internationally recognized for determination of the physiological race of PM by statistically assessing disease responses under defined environmental conditions. So far, nearly 50 physiological races and approximately 36 resistant melon germplasm have been identified worldwide (Alvarez et al. 2000; Bertrand 2002; Cohen et al. 2002; Floris and Alvarez 1995; Harwood and Markarian 1968; Hosoya et al. 1999; Jagger et al. 1938; McCreight 2002, 2006; McCreight and Coffey 2011; Mohamed et al. 1995; Pitrat et al. 1998; Sowell and Corley 1974; Thomas 1978). Hosoya et al. (1999) differentiated 11 physiological races of $P$. xanthii including 0, 1, 2F, and 2US in Japan. McCreight (2002) evaluated a set of melon germplasm responding to different races of $P$. xanthii, and reported 20 accessions resistant to physiological race 1,10 cultivars resistant to physiological race 2 and the variety 'PI 124111' resistant to physiological races $1,2,4$, and 5. P. xanthii physiological races are recognized as $0,1 \mathrm{~J}, 1 \mathrm{Sp}, 1 \mathrm{M}, 1 \mathrm{IV}, 1 \mathrm{SJ}, 1 \mathrm{~S}, 1 \mathrm{Ti}, 1 \mathrm{Tu}, 2 \mathrm{US}$, 2S, 2F, 2Z, 2a, 2b, 3, 3c, 3d, 4, 5, N1, N2, N3, N4, 6, F, G, and H (Alvarez et al. 2000; Bertrand 2002; Cohen et al. 2002; Floris and Alvarez 1995; Harwood and Markarian 1968; Jagger et al. 1938; Mohamed et al. 1995; Pitrat et al. 1998; Sowell and Corley 1974; Thomas 1978).

Breeding of PM-resistant melon cultivars to races that occur in the regions where the cultivars will be cultivated is a high priority. In the present study, race $2 \mathrm{~F}$ was used for inoculation to identify genes and QTLs resistant to PM. The results provide solid fundamental information that will be useful for future marker-assisted selection

TABLE 3. Primer sequences of Kompetitive allele specific PCR (KASP) markers linked to powdery mildew resistance locus Pm2.1 and cleaved amplified polymorphic sequence (CAPS) markers linked to $p m 12.1$, and compliance rate in 93 melon accessions ${ }^{\mathrm{a}}$

\begin{tabular}{|c|c|c|}
\hline Marker name (restriction enzyme) & Primer sequence & Compliance rate \\
\hline $\operatorname{snp} 5(-)$ & $\begin{array}{l}\text { Primer_AlleleX: } \\
\text { GAAGGTGACCAAGTTCATGCTGGCACAATGGTATTTCAGAGAAGATAT } \\
\text { Primer_AlleleY: } \\
\text { GAAGGTCGGAGTCAACGGATTGCACAATGGTATTTCAGAGAAGATAG } \\
\text { Primer_Common: CCCTAAAGCCGAATCCAATTAAAACAAGTA }\end{array}$ & $94.6 \%$ \\
\hline snp6(-) & $\begin{array}{l}\text { Primer_AlleleX: } \\
\text { GAAGGTGACCAAGTTCATGCTAAAACAAAAAACCAAGCAAGATAGCCG } \\
\text { Primer_AlleleY: } \\
\text { GAAGGTCGGAGTCAACGGATTCAAAAACAAAAAACCAAGCAAGATAGCCA } \\
\text { Primer_Common: ATTGTTTGGGCCTCATTTGGAGTTGATT }\end{array}$ & $94.6 \%$ \\
\hline $12 \mathrm{C} 8(\operatorname{Taq} \mathrm{I})$ & $\begin{array}{l}\text { Forward primer: GAGATGCCAACATTCCAACTAAG } \\
\text { Reverse primer: GGTACACTTCTATTCTCGTCTATCA }\end{array}$ & $92.4 \%$ \\
\hline $12 \mathrm{C} 13(\mathrm{XhoI})$ & $\begin{array}{l}\text { Forward primer: TGGACTAGGCATACGATCACATAG } \\
\text { Reverse primer: AGGAGTCGTGAGCCAGGAAT }\end{array}$ & $92.4 \%$ \\
\hline
\end{tabular}

a Compliance rate is the percentage of 93 melon accessions that match phenotypes and genotypes after genotyping using the markers.

TABLE 4. Functional annotation of the predicted powdery mildew resistance candidate genes in the candidate regions on melon chromosomes 2 and 12

\begin{tabular}{|c|c|c|}
\hline Gene ID & Description of gene function & Chromosome \\
\hline MELO3C015353 & Disease resistance protein & 2 \\
\hline MELO3C015354 & Disease resistance family protein/LRR family protein & 2 \\
\hline MELO3C002438 & Ankyrin repeat family protein & 12 \\
\hline MELO3C002439 & Ankyrin repeat family protein, putative & 12 \\
\hline MELO3C002440 & DUF4283 domain protein & 12 \\
\hline MELO3C002441 & Ankyrin repeat family protein & 12 \\
\hline MELO3C002442 & Aspartic proteinase & 12 \\
\hline
\end{tabular}


breeding programs aimed at developing varieties that are resistant to the dominant race in specific regions.

As far as we are aware, the present study is the first to report two putative QTLs, Pm2.1 and pm12.1, with dominant epistatic effects on chromosomes 2 and 12 from melon accession PMR 6. Previous marker-trait association studies including BSA and GWAS have revealed several genes and QTLs conferring resistance to PM on chromosomes or linkage groups 2, 5, and 12 (Supplementary Table S1) (Fazza et al. 2013; Pitrat 1991; Zhang et al. 2012). Amanullah (2016) detected 12 GWAS signals for PM resistance, among which seven were consistent with the previous results and five loci were novel. Most of the loci conferred resistance to $P$. xanthii race 1, and only two loci conferred resistance to $P$. xanthii race $2 F$. Further, the resistance loci were derived from different melon materials. Therefore, it is necessary to screen more resistance loci for improvement of PM resistance by pyramiding race-specific genes, most of which acted as a single gene under the condition of distinguishing physiological races. The interaction of two resistance loci with dominant epistatic effects provides a novel insight into development of durable resistance to PM in melon.

Currently, $P m-2 F$ is the only locus that is nearly fine-mapped for resistance to $P$. xanthii race $2 \mathrm{~F}$ in melon. Other resistance genes or QTLs on chromosome/linkage group 2 provides resistance to other physiological races. We positioned the locus Pm2.1 conferring resistance to $P$. xanthii race $2 \mathrm{~F}$ on chromosome 2, supporting the results of Zhang et al. (Zhang et al. 2012), who fine-mapped a dominant locus $P m-2 F$ against race $2 \mathrm{~F}$ with SSR markers in the same interval on chromosome $2 . P m-2 F$ is a dominant gene. Pm2.1 is speculated to be the same dominant gene as $P m-2 F$, with the same genetic laws and candidate genes. Therefore, based on the segregation ratio of the $F_{2}$ population and the interaction between the two loci, $p m 12.1$ is presumed to be a recessive gene. To the best of our knowledge, we mapped locus pm12.1 conferring resistance to $P$. xanthii race $2 \mathrm{~F}$ on chromosome 12 for the first time in the present study. Li et al. (2017) mapped a locus BPm12.1 conferring resistance to race 1 in the interval of $22,804,373$ to $22,883,118 \mathrm{bp}$ on chromosome 12, which is close to the location of pm12.1. Other resistance genes or QTLs on chromosome/linkage group 12 conferred resistance to other physiological races. Therefore, we hypothesize that the region harboring pm12.1 might play a key role in regulation of melon resistance to $\mathrm{PM}$ including race 1 , race $2 \mathrm{~F}$, or other races.

We investigated the subspecific differences in patterns of SNPs for two candidate segments on chromosomes 2 and 12. The difference in $\pi$ reflects the extent to which the population deviates from neutral evolution at the level of nucleotide polymorphism and is an ideal model of mutation-drift balance (Li 1997; Nei 1987; Wright 1931). Wright (1931) first proposed a formula to estimate the population genetic differentiation coefficient Fst for assessment of the degree of differentiation of subpopulations. Due to population subdifferentiation contributed by natural selection, Cavalli-Sforza (1966) first suggested use of the degree of differentiation between groups to infer the role of natural selection. Comparisons of the $\pi$ and Fst values among three subspecies populations showed high positional nucleotide polymorphisms in two candidate segments. Particularly, the $\pi$ value of $C$. melo ssp. agrestis suddenly increased in two candidate segments to a level similar to C. melo ssp. melo and the intermediate type. The $\pi$ value of melon is generally low because a relatively close relationship exists among melons that is caused by natural selection during the evolutionary process. The higher $\pi$ value in the PM resistance gene region shows that this segment is not conserved with abundant variations, indicating no significant correlation between the emergence of PM resistance with natural selection during the evolutionary process in melon. Therefore, we hypothesize that resistance to PM might be caused by a rich variation in the nonconserved segments of the genome and is preserved during evolution. Further study should focus on gaining a molecular understanding of the biological process involved in the emergence and evolution of PM resistance genes.
In summary, we mapped two PM resistance loci, Pm2.1 and pm12.1, on chromosomes 2 and 12 in melon using BSA and QTL analysis. The phenotyping data of six generations of melon
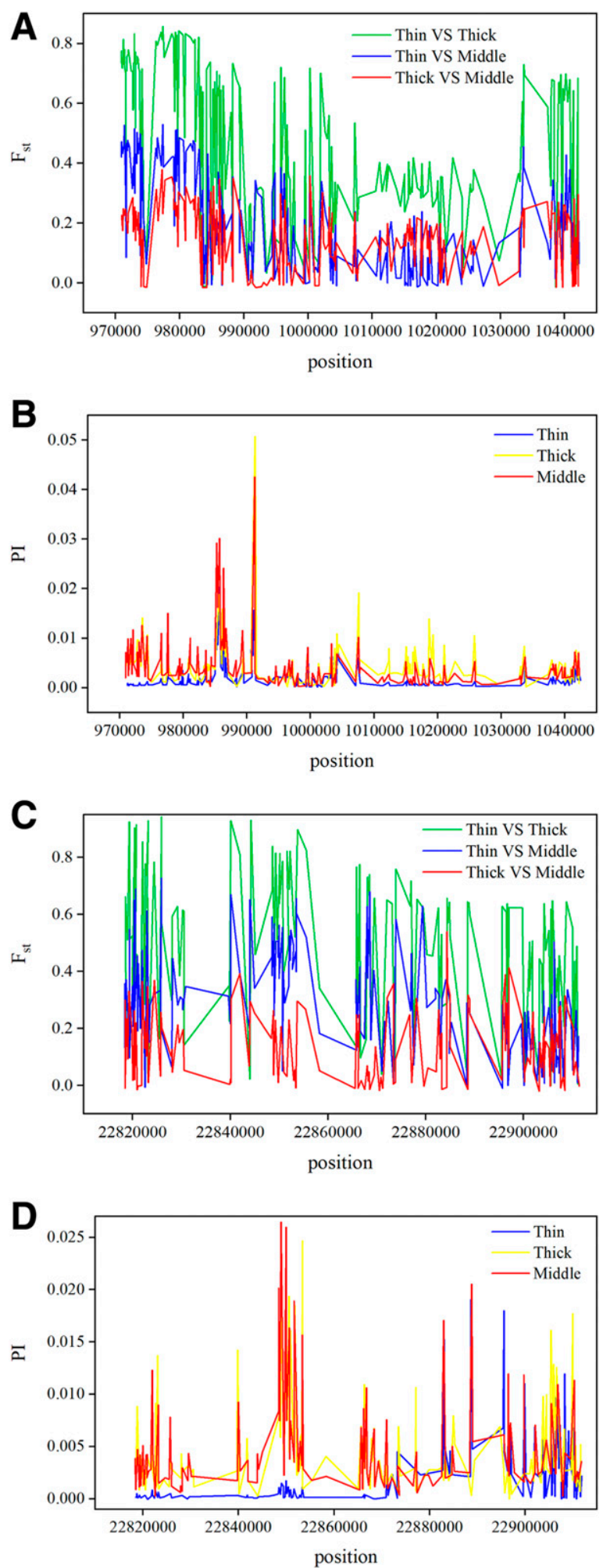

Fig. 5. A, Fixation index (Fst) values between three melon groups (Cucumis melo subsp. agrestis, C. melo subsp. melo, and intermediate type [interspecific between the two species]) of the powdery mildew resistance candidate region on chromosome 2 . B, Nucleotide diversity $(\pi)$ values of three melon groups in the candidate region on chromosome 2 . C, Fst values between three melon groups of the candidate region on chromosome 12 . D, $\pi$ values of three melon groups in the candidate region on chromosome 12 . 
demonstrated the dominant epistasis effect of PM-resistance locus Pm2.1 on the locus pm12.1. $\pi$ and Fst of three groups revealed no significant association of selection of the candidate interval with the occurrence of PM resistance during melon evolution. The two PM resistance loci and SNP markers developed in the present study provide a promising tool to accelerate breeding for durable resistance to PM, thus contributing to sustainable agriculture that includes melon PM control.

Data availability statement. The data that support the findings of this study are available from the corresponding authors, Dr. Gao and Prof. Luan, upon reasonable request.

\section{LITERATURE CITED}

Allen, G. C., Flores-Vergara, M. A., Krasynanski, S., Kumar, S., and Thompson, W. F. 2006. A modified protocol for rapid DNA isolation from plant tissues using cetyltrimethylammonium bromide. Nat. Protoc. 1: 2320-2325.

Alvarez, J. M., Gómezguillamón, M. L., Torés, N. A., Cánovas, I., and Floris, E. 2000. Virulence differences between two Spanish isolates of Sphaerotheca fuliginea race 2 on melon. Acta Hortic. 510:67-69.

Amanullah, S. 2016. Genome-wide association study of powdery mildew resistance in a worldwide collection of melon (Cucumis melo L.) Germplasm. Pages 50-53 in: Cucurbitaceae 2016. U. Elżbieta, H. Kozik, and S. Paris, eds. ASHS Press, Alexandria, VA.

Bardin, M., Carlier, J., and Nicot, P. C. 1999a. Genetic differentiation in the French population of Erysiphe cichoracearum, a causal agent of powdery mildew of cucurbits. Plant Pathol. 48:531-540.

Bardin, M., Dogimont, C., Nicot, P., and Pitrat, M. 1999b. Genetic analysis of resistance of melon line PI 124112 to Sphaerotheca fuliginea and Erysiphe cichoracearum studied in recombinant inbred lines. Acta Hortic.: 163-168.

Bertrand, F. 2002. AR Hales Best Jumbo, a new differential melon variety for P. xanthii $(\mathrm{Px})$ races in leaf disk tests. Pages 234-237 in: Cucurbitaceae. D. N. Maynard, ed. ASHS Press, Alexandria, VA.

Broman, K. W., Wu, H., Sen, S., and Churchill, G. A. 2003. R/qtl: QTL mapping in experimental crosses. Bioinformatics 19:889-890.

Daryono, B. S., and Yambise, H. C. 2018. Deteksi Gen Ketahanan Terhadap Powdery Mildew Pada Melon (Cucumis melo L. 'Aramis'). Biogenesis J. Ilmiah Biologi 6:124-130.

Cavalli-Sforza, L. L. 1966. Population structure and human evolution. Proc. R. Soc. Lond. B Biol. Sci. 164:362-379.

Cheng, H., Kong, W., Su, Y., Liu, D., and He, Q. 2011. Identification on powdery mildew and physiological race of melon in China. J Changjiang Veg. 18:1-5.

Cingolani, P., Platts, A., Wang Le, L., Coon, M., Nguyen, T., Wang, L., Land, S. J., Lu, X., and Ruden, D. M. 2012. A program for annotating and predicting the effects of single nucleotide polymorphisms, SnpEff: SNPs in the genome of Drosophila melanogaster strain w1118; iso-2; iso-3. Fly 6:80-92.

Cohen, R., Burger, Y., and Shraiber, S. 2002. Physiological races of P. xanthii $(\mathrm{Px})$ : Factors affecting their identification and the significance of this knowledge. Pages 181-187 in: Cucurbitaceae. ASHS Press, Alexandria, VA.

Cohen, Y., Eyal, H., and Hanania, J. 1990. Ultrastructure, autofluorescence, callose deposition and lignification in susceptible and resistant muskmelon leaves infected with the powdery mildew fungus Sphaerotheca fuliginea. Physiol. Mol. Plant Pathol. 36:191-204.

Danecek, P., Auton, A., Abecasis, G., Albers, C. A., Banks, E., DePristo, M. A., et al. 2011. The variant call format and VCFtools. Bioinformatics 27: 2156-2158.

Dogimont, C. 2011. Gene list 2011 for melon. T. C. Wehner, ed. Cucurbit Genetics Cooperative Rep. 133:104-133.

Fazza, A. C., Dallagnol, L. J., Fazza, A. C., Monteiro, C. C., Lima, B. M. D., Wassano, D. T., and Camargo, L. E. A. 2013. Mapping of resistance genes to races 1, 3 and 5 of Podosphaera xanthii in melon PI 414723. Crop Breed. Appl. Biotechnol. 13:349-355.

Floris, E., and Alvarez, J. M. 1995. Genetic analysis of resistance of three melon lines to Sphaerotheca fuliginea. Euphytica 81:181-186.

Fukino, N., Ohara, T., Monforte, A. J., Sugiyama, M., Sakata, Y., Kunihisa, M., and Matsumoto, S. 2008. Identification of QTLs for resistance to powdery mildew and SSR markers diagnostic for powdery mildew resistance genes in melon (Cucumis melo L.). Theor. Appl. Genet. 118:165-175.

Hao, L. U., Wang, X. L., Gao, X. W., Ning, X. F., Chen, J., and Guan, L. I. 2015. Inheritance and location of powdery mildew resistance gene in melon PMR 6. Acta Hortic Sin. 42:1121-1128.

Harwood, R. R., and Markarian, D. 1968. The inheritance of resistance to powdery mildew in the cantaloupe variety Seminole. J. Hered. 59:126-130.

Hollomon, D., Wheeler, I., Be'Langer, R., Bushnell, W., Dik, A., and Carver, T. 2002. Controlling powdery mildews with chemistry. Pages 249-255 in: The Powdery Mildews: A Comprehensive Treatise. R. R. Belanger, W. R.
Bushnell, A. J. Dik, and T. L. W. Carver, eds. The American Phytopathological Society, St. Paul, MN.

Hosoya, K., Kuzuya, M., Murakami, T., Kato, K., Narisawa, K., and Ezura, H. 2000. Impact of resistant melon cultivars on Sphaerotheca fuliginea. Plant Breed. 119:286-288.

Hosoya, K., Narisawa, K., Pitrat, M., and Ezura, H. 1999. Race identification in powdery mildew (Sphaerotheca fuliginea) on melon (Cucumis melo) in Japan. Plant Breed. 118:259-262.

Hudson, D. O. R., Lucas, D. S. S., Guilherme, M. M. D., Marcus, V. M., Leila, T. B., and James, D. M. 2018. Cucurbits powdery mildew race identity and reaction of melon genotypes. Pesqui. Agropecu. Trop. 47:440-447.

Jagger, I. C., Whitaker, T. W., and Porter, D. R. 1938. A new biotic form of powdery mildew on muskmelon in the Imperial Valley of California. Plant Dis. Rep. 22:275-276.

Jordi, G.-M., Andrej, B., Walter, S., Michael, B., Gisela, M., Victor, M.-G., et al. 2012. The genome of melon (Cucumis melo L.). Proc. Natl. Acad. Sci. USA 109:11872-11877.

Kim, H.-T., Park, J.-I., Robin, A. H. K., Ishikawa, T., Kuzuya, M., Horii, M., Yashiro, K., and Nou, I.-S. 2016. Identification of a new race and development of DNA markers associated with powdery mildew in melon. Plant Breed. Biotechnol. 4:225-233.

Kř́stková, E., Lebeda, A., and Sedláková, B. 2009. Species spectra, distribution and host range of cucurbit powdery mildews in the Czech Republic, and in some other European and Middle Eastern countries. Phytoparasitica 37:337-350.

Lebeda, A., Mcgrath, M. T., and Sedláková, B. 2010. Pages 221-246 in: Fungicide Resistance in Cucurbit Powdery Mildew Fungi. Fungicides InTech, Rijeka.

Li, B., Zhao, Y., Zhu, Q., Zhang, Z., Fan, C., Amanullah, S., Gao, P., and Luan, F. 2017. Mapping of powdery mildew resistance genes in melon (Cucumis melo L.) by bulked segregant analysis. Sci. Hortic. (Amsterdam) 220: 160-167.

Li, H., Handsaker, B., Wysoker, A., Fennell, T., Ruan, J., Homer, N., Marth, G., Abecasis, G., Durbin, R., and 1000 Genome Project Data Processing Subgroup. 2009. The sequence alignment/map format and SAMtools. Bioinformatics 25:2078-2079.

Li, W. H. 1997. Page 487 in: Molecular Evolution. Sinauer Associates, Sunderland, MA.

Ma, H., Wei, Z., Zu, Y., and Luan, F. 2011. Physiological races identification of powdery mildew on main cucurbits in Heilongjiang Province during 2009-2010. Acta Phytophylac. Sin. 38:287-288.

Ma, H., Zu, Y., and Luan, F. 2009. Identification of melon germplasm resistance to powdery mildew in seedling stage. J. Northeast Agric. Univ. 40: $18-23$.

McCreight, J. D. 2002. Reactions of 20 melon cultigens to powdery mildew race 2US. Pages 72-77 in: Cucurbitaceae 2002. D. N. Maynard and D. W. Wolff, eds. ASHS Press, Alexandria, VA.

McCreight, J. D. 2006. Melon-powdery mildew interactions reveal variation in melon cultigens and Podosphaera xanthii races 1 and 2. J. Am. Soc. Hortic. Sci. 131:59-65.

McCreight, J. D., and Coffey, M. D. 2011. Inheritance of resistance in melon PI 313970 to cucurbit powdery mildew incited by Podosphaera xanthii race S. HortScience 46:838-840.

McCreight, J. D., Coffey, M. D., Turini, T. A., and Matheron, M. E. 2005. Field evidence for a new race of powdery mildew on melon. HortScience 40:888.

Meng, L., Li, H., Zhang, L., and Wang, J. 2015. QTL IciMapping: Integrated software for genetic linkage map construction and quantitative trait locus mapping in biparental populations. Crop J. 3:269-283.

Mohamed, Y. F., Bardin, M., Nicot, P. C., and Pitrat, M. 1995. Causal agents of powdery mildew of cucurbits in Sudan. Plant Dis. 79:634-636.

Nei, M. 1987. Page 512 in: Molecular Evolutionary Genetics. Columbia University Press, New York.

Ning, X., Wang, X., Gao, X., Zhang, Z., Zhang, L., Yan, W., et al. 2014. Inheritances and location of powdery mildew resistance gene in melon Edisto47. Euphytica 195:345-353.

Perchepied, L., Bardin, M., Dogimont, C., and Pitrat, M. 2005. Relationship between loci conferring downy mildew and powdery mildew resistance in melon assessed by quantitative trait loci mapping. Phytopathology 95 : 556-565.

Perin, C., Hagen, S., De Conto, V., Katzir, N., Danin-Poleg, Y., Portnoy, V., Baudracco-Arnas, S., Chadoeuf, J., Dogimont, C., and Pitrat, M. 2002. A reference map of Cucumis melo based on two recombinant inbred line populations. Theor. Appl. Genet. 104:1017-1034.

Pino, D. D., Olalla, L., Pérez-García, A., Rivera, M. E., García, S., Moreno, R., Vicente, A., and Tores, J. A. 2002. Occurrence of races and pathotypes of cucurbit powdery mildew in southeastern Spain. Phytoparasitica 30:459-466.

Pitrat, M. 1991. Linkage groups in Cucumis melo L. Rep. Cucurbit Genet. Coop. 82:406-411. 
Pitrat, M., Dogimont, C., and Batdin, M. 1998. Resistance to fungal diseases of foliage in melon. Pages 167-173 in: Cucurbitaceae. Evaluation and enhancement of cucurbit germplasm. J. D. McCreight, ed. ASHS Press, Alexandria, VA.

Pryor, D. E., Whitaker, T. W., and Davis, G. N. 1946. The development of powdery mildew resistant cantaloupes. Proc. Am. Soc. Hortic. Sci. 47:347-356.

Sathishkumar, N., Kim, H. K., Thamilarasan, S. K., Veerappan, K., Park, J. I., and Nou, S. 2016. Whole genome resequencing and characterization of powdery mildew disease-associated allelic variation in melon. PLoS One 11:e0157524.

Sowell, G. J., and Corley, L. W. 1974. Severity of race 2 of Sphaerotheca fuliginea (Schlecht) Poll. on muskmelon introductions reported resistant to powdery mildew. HortScience 9:398-399.

Thomas, E. C. 1978. A new biological race of powdery mildew of cantaloupes. Plant Dis. Rptr. 62:223.

Wang, X., Li, G., Gao, X., Xiong, L., Wang, W., and Han, R. 2011. Powdery mildew resistance gene $(P m-A N)$ located in a segregation distortion region of melon LGV. Euphytica 180:421-428.

Wang, Y. H., Wu, D. H., Huang, J. H., Tsao, S. J., Hwu, K. K., and Lo, H. F. 2016. Mapping quantitative trait loci for fruit traits and powdery mildew resistance in melon (Cucumis melo L.). Bot. Stud. (Taipei, Taiwan) 57:19.

Wheeler, B. E. J., and Kent, G. C. 1969. An introduction to plant diseases. Q. Rev. Biol. 45:299-300.

Wright, S. 1931. Evolution in Mendelian populations. Genetics 16:97-159.

Xu, X., Liu, X., Yan, Y., Wang, W., Gebretsadik, K., Qi, X., Xu, Q., and Chen, X. 2019. Comparative proteomic analysis of cucumber powdery mildew resistance between a single-segment substitution line and its recurrent parent. Hortic Res-England. 6:115.

Yuste-Lisbona, F. J., Capel, C., Gomez-Guillamon, M. L., Capel, J., Lopez-Sese, A. I., and Lozano, R. 2011a. Codominant PCR-based markers and candidate genes for powdery mildew resistance in melon (Cucumis melo L.). Theor. Appl. Genet. 122:747-758.

Yuste-Lisbona, F. J., Capel, C., Sarria, E., Torreblanca, R., Gómez-Guillamón, M. L., Capel, J., Lozano, R., and Lopez-Sese, A. I. 2011b. Genetic linkage map of melon (Cucumis melo L.) and localization of a major QTL for powdery mildew resistance. Mol. Breed. 27:181-192.

Zhang, C., Ren, Y., Guo, S., Zhang, H., Gong, G., Du, Y., and Xu, Y. 2012. Application of comparative genomics in developing markers tightly linked to the $\mathrm{Pm}-2 \mathrm{~F}$ gene for powdery mildew resistance in melon (Cucumis melo L.). Euphytica 190:157-168.

Zhang, H., Guo, S., Gong, G., Yi, R., Davis, A. R., and Yong, X. 2011. Sources of resistance to race $2 \mathrm{WF}$ powdery mildew in U.S. watermelon plant introductions. HortScience 46:1349-1352.

Zhao, G., Lian, Q., Zhang, Z., Fu, Q., He, Y., Ma, S., et al. 2019. A comprehensive genome variation map of melon identifies multiple domestication events and loci influencing agronomic traits. Nat. Genet. 51: 1607-1615.

Zheng, Y., Fei, X., Li, Q., Wang, G., Nan, L., Gong, Y., Li, L., Chen, Z.-H., and $\mathrm{Xu}, \mathrm{S}$. 2018. QTL mapping combined with bulked segregant analysis identify SNP markers linked to leaf shape traits in Pisum sativum using SLAF sequencing. Front. Genet. 9:615. 